\title{
United States Pharmacopeia Safety Review of Willow Bark
}

\author{
Authors \\ Affiliations \\ 1 U.S. Pharmacopeial Convention, Rockville, MD, USA \\ 2 2015-2020 United States Pharmacopeia Dietary Supple- \\ ments Admission Evaluations Joint Standard Setting Sub- \\ committee (DSAE JS3), Rockville, MD, USA
}

Hellen A. Oketch-Rabah ${ }^{1}$, Robin J. Marles ${ }^{2}$, Scott A. Jordan², Tieraona Low Dog ${ }^{2}$

Key words

salix, Salicaceae, willow bark, Reye syndrome, salicin, salicylic acid, salicylates, dietary supplements

$\begin{array}{ll}\text { received } & \text { July 8, } 2019 \\ \text { revised } & \text { September 3, } 2019 \\ \text { accepted } & \text { September 18, } 2019\end{array}$

Bibliography

DOI https://doi.org/10.1055/a-1007-5206

Published online October 11, 2019 | Planta Med 2019; 85:

1192-1202 @ Georg Thieme Verlag KG Stuttgart · New York | ISSN 0032-0943

Correspondence

Hellen Oketch-Rabah, Ph.D.

United States Pharmacopeia (USP), DSHM

12601 Twinbrook Pkwy, Rockville, MD 20852, USA

Phone: + 13012303249 , Fax: + 13018168182

hao@usp.org

\section{ABSTRACT}

Willow bark (Salix spp.) is an ingredient in some dietary supplements. No serious adverse effects were reported from trials of willow bark extracts delivering $120-240 \mathrm{mg}$ salicin (the purported active constituent) daily for up to 8 weeks. All studies involved adults only; none involved special subpopulations such as pregnant or breastfeeding women, or children. The most common adverse effects associated with willow bark are gastrointestinal; a few allergic reactions were also reported. Some publications advise caution when taking willow bark. There is a risk of increased bleeding in vulnerable individuals, salicylates cross the placenta and are eliminated slowly in newborns, some persons are sensitive or allergic to aspirin, and children are at risk of Reye syndrome. Concurrent use with other salicylate-containing medicines increases these risks. Metabolism of $240 \mathrm{mg}$ salicin from willow bark could yield $113 \mathrm{mg}$ of salicylic acid, yet dietary supplement products are not required to be labeled with warnings. In contrast, over-the-counter low-dose aspirin ( $81 \mathrm{mg}$ strength), which delivers $62 \mathrm{mg}$ salicylic acid, is required by law to include cautions, warnings, and contraindications related to its use in pregnant and nursing women, children, and other vulnerable subpopulations, e.g., those using anticoagulants. In the interest of protecting public health, the United States Pharmacopeia has included a cautionary labeling statement in the United States Pharmacopeia Salix Species monograph as follows: "Dosage forms prepared with this article should bear the following statement: 'Not for use in children, women who are pregnant or nursing, or by persons with known sensitivity to aspirin."”

\section{Introduction}

Willow bark ( $\bullet$ Fig. 1 ) is obtained from the bark of various species of Salix (willow tree) belonging to the Salicaceae family of plants. Roughly 500 species of the genus Salix are known, mainly, in Europe and North America [1,2]. The most popular species used medicinally are Salix alba L., Salix nigra Marshall, Salix purpurea L., Salix daphnoides Vill., and Salix $\times$ fragilis $\mathrm{L}$. These species contain higher amounts of salicylate precursors compared to most other species [1]. Willow bark has been used as a medicine since at least the days of Hippocrates (400 BC) when physicians advised their patients to chew the bark to reduce fever and inflammation [3]. Historical records indicate that Babylonians used willow tree bark or leaf extracts to treat common fever, pain, and inflammation.
According to one clay tablet dating back 4000 years, the Sumerians were the first known civilization to register medical prescriptions for pain, one prescription being Salix spp. [4].

Chemical investigation into therapeutically active substances in willow extract started with extraction of the bark of Salix $\times$ latifolia J. Forbes by Wilkinson in 1803. S. × latifolia bark extract was partially purified and called salicin after the genus name Salix by Buchner in 1828 and it was obtained in pure crystalline form by Leroux in 1829. Hydrolysis yielded salicyl alcohol, which was also isolated by Pagenstecher in 1835 from meadow sweet flowers [Spiraea ulmaria L., now known as Filipendula ulmaria (L.) Maxim. in the Family Rosaceae]. Oxidation of salicyl alcohol yielded salicylic acid, which was also produced during that same period by oxidation of salicylic aldehyde. Large-scale synthesis of salicylic acid was accomplished for 


$\begin{array}{ll}\text { ABBREVIATIONS } \\ \text { AEs } & \text { adverse events } \\ \text { Arhus LBP } & \text { Arhus lower back pain } \\ \text { ASA } & \text { acetylsalicylic acid } \\ \text { DER } & \text { drug extract ratio } \\ \text { DS } & \text { dietary supplement } \\ \text { DSLD } & \text { Dietary Supplement Label Database } \\ \text { GI } & \text { gastrointestinal } \\ \text { LBP } & \text { lower back pain } \\ \text { MSDs } & \text { musculoskeletal disorders } \\ \text { NIH } & \text { National Institute of Health } \\ \text { NSAIDs } & \text { nonsteroidal anti-inflammatory drugs } \\ \text { OA } & \text { osteoarthritis } \\ \text { RA } & \text { rheumatoid arthritis } \\ \text { TPI } & \text { total pain index } \\ \text { WBE } & \text { willow bark extract } \\ \text { WOMAC } & \text { Western Ontario and McMaster Universities } \\ & \text { Osteoarthritis Index } \\ \end{array}$

drug production and its acetylation to acetylsalicylic acid to reduce the adverse effect of gastrointestinal bleeding was developed by Hoffman and Eichengrun in 1897, leading to the patenting of aspirin ("a" for "acetyl" and "spirin" meaning from Spiraea) in 1899 by the Bayer Company. Thus, chemical investigations of the medicinal properties of willow bark led to the discovery of the synthetic drug aspirin; it is a common misconception that willow bark is a source of aspirin, which it is not [5].

Willow bark was included as part of the Materia Medica in the first volume of the U.S. Pharmacopeia published in 1820 [6]. Today, willow bark is used for the treatment of pain, particularly, LBP, osteoarthritis $(\mathrm{OA})$, headaches, and inflammatory conditions such as tendinitis and bursitis [7].

In the U.S., willow bark is a dietary ingredient in numerous DSs available in the market. Because of its popularity, the United States Pharmacopoeia (USP) developed quality standards for willow bark ingredients under the title Salix Species Bark. Prior to developing a DS monograph, USP customarily performs an Admission Evaluation [8]. This evaluation was done following the guidelines for admission of DSs into the monograph development process [9], and includes an assessment to ascertain that an ingredient does not present a serious risk to human health. The USP quality monographs include the name/title of the ingredient, the definition, specifications, and instructions for packaging, storage, and labeling requirements. The specifications consist of a series of tests, procedures for the tests, and acceptance criteria [10]. These tests and procedures require the use of official USP Reference Standards [11]. In this paper, we focus on the safety of willow bark as a dietary ingredient in DSs and present a case for the need to include a label caution statement on DS products containing willow bark that claim compliance with USP standards for willow bark.

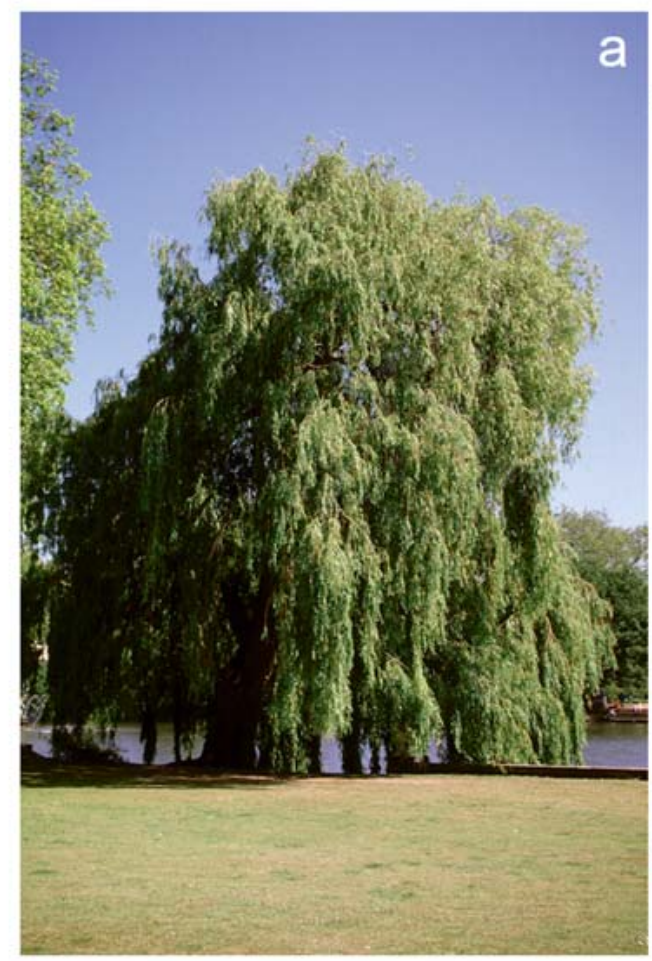

2
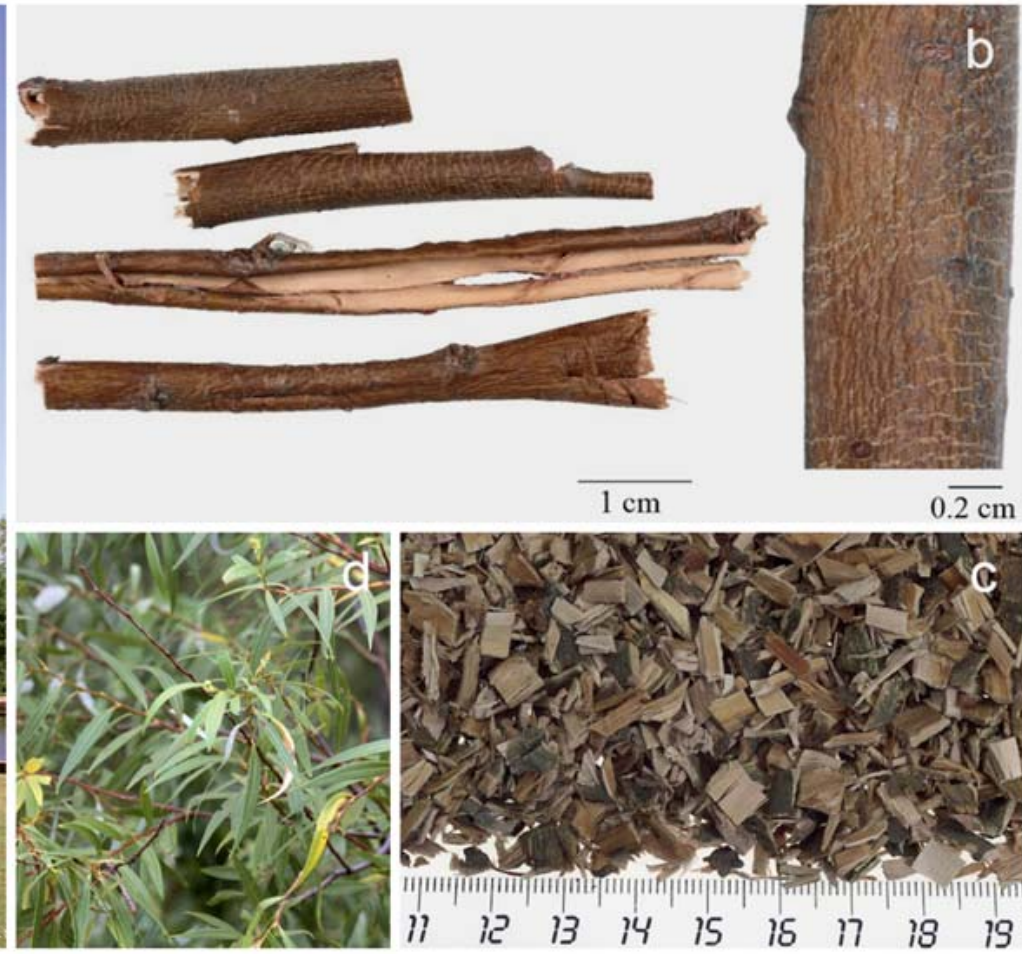

$0 . \overline{2 \mathrm{~cm}}$

- Fig. 1 Clockwise from upper left: A willow tree (๔ PLANTAPHILE); B dried branches of Salix alba from which willow bark is harvested and a closeup of the bark (USP, Dietary Supplements Compendium (DSC) 2019, Supplementary Information, Illustrations, Salix Species Bark); C chopped willow bark material of commerce (@ PLANTAPHILE); D willow leaves (৫ PLANTAPHILE). 


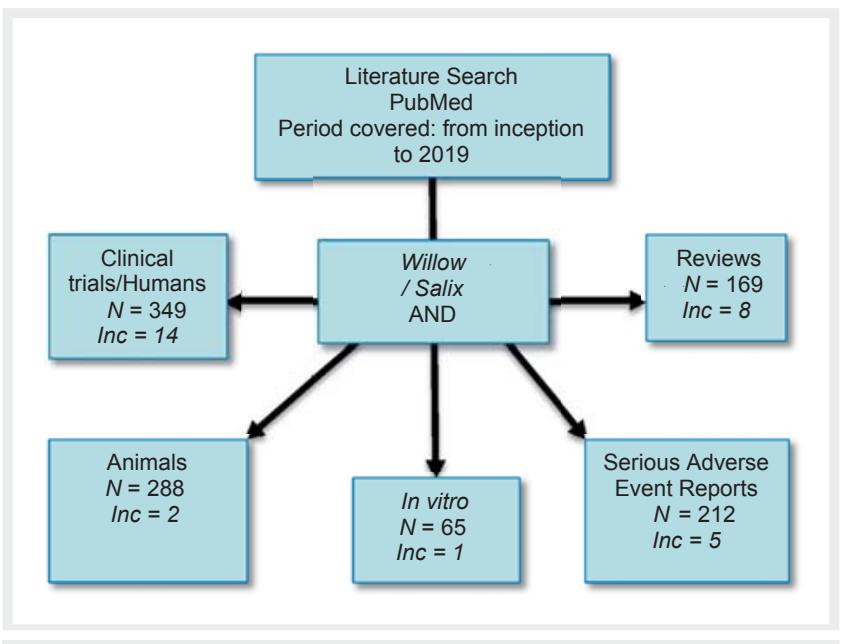

- Fig. 2 Literature search strategy, where N: represents number of articles retrieved, Inc: represents the number of articles included in the review. Only studies that evaluated materials containing willow bark willow bark extract as a single active ingredient were included.

\section{Literature Retrieval Strategy}

A search was done in PubMed using the search terms "willow" or "salix" combined with the following terms: safety, clinical trials, reviews, humans, in vitro, adverse effects or side effects, pharmacokinetic, and phytochemistry, covering the period from inception of PubMed to 2019. The retrieved titles and abstracts were reviewed by two co-authors of this review, H.A. O.-R. and T.L.D., to determine articles relevant to safety. Only studies that evaluated materials containing willow bark as a single active ingredient were included. Data was extracted into Excel tables and reviewed for inclusion by H.A.O.-R. and T.L.D. Where the two researchers disagreed, they discussed and reached a consensus.
- Fig. 2 is a graphical representation of the search strategy, showing all articles retrieved from PubMed and the number of articles that are included in this review.

\section{Willow Bark Phytochemistry and Pharmacopeial Quality}

The willow species most popularly used in commerce, S. alba, S. nigra, S. daphnoides, S. fragilis, and S. purpurea, have a salicylate content ranging from 1.5 to $15 \%[12,13]$. Among these, S. daphnoides, $S$. fragilis, and $S$. purpurea are reported to yield the highest amounts of salicylates [14]. Salicylates are derivatives of salicylic acid naturally present in willow bark. Salicin, a salicylate derivative, is a glycoside of salicyl alcohol ( $\triangleright$ Fig. 3). Salicin and its related compound(s) has been used as a marker of biological activity and quality of willow bark [15]. However, other constituents are also used as markers including derivatives of salicin such as salicortin, 2'-O-acetylsalicortin, salicin-7-sulfate, and tremulacin, flavonoids, condensed tannins (8-20\%), and catechins. The concentration of salicylates varies significantly between willow species and with the seasons, but there is only limited variation in phytochemical content between high-salicylate commercial species such as S. purpurea and S. daphnoides, as shown in > Table 1 [15-17]. The similar chemical profiles, morphology, and anatomy of the barks of the species cited above explains their interchangeability in commerce.

In addition to salicylates, willow bark also contains polyphenols, including flavonoids, proanthocyanidins, and tannins that are thought to contribute to its biological activity [18]. Flavonoids such as naringenin, isosalipurpuroside, or eriodictyol usually constitute up to $20 \%$ in WBE $[19,20]$. Other compounds identified in the bark of Salix species are $p$-hydroxybenzoic, vanillic, cinnamic, p-coumaric, ferulic, caffeic acids, and other phenolic acids. In a study that investigated the antioxidative compounds in the bark

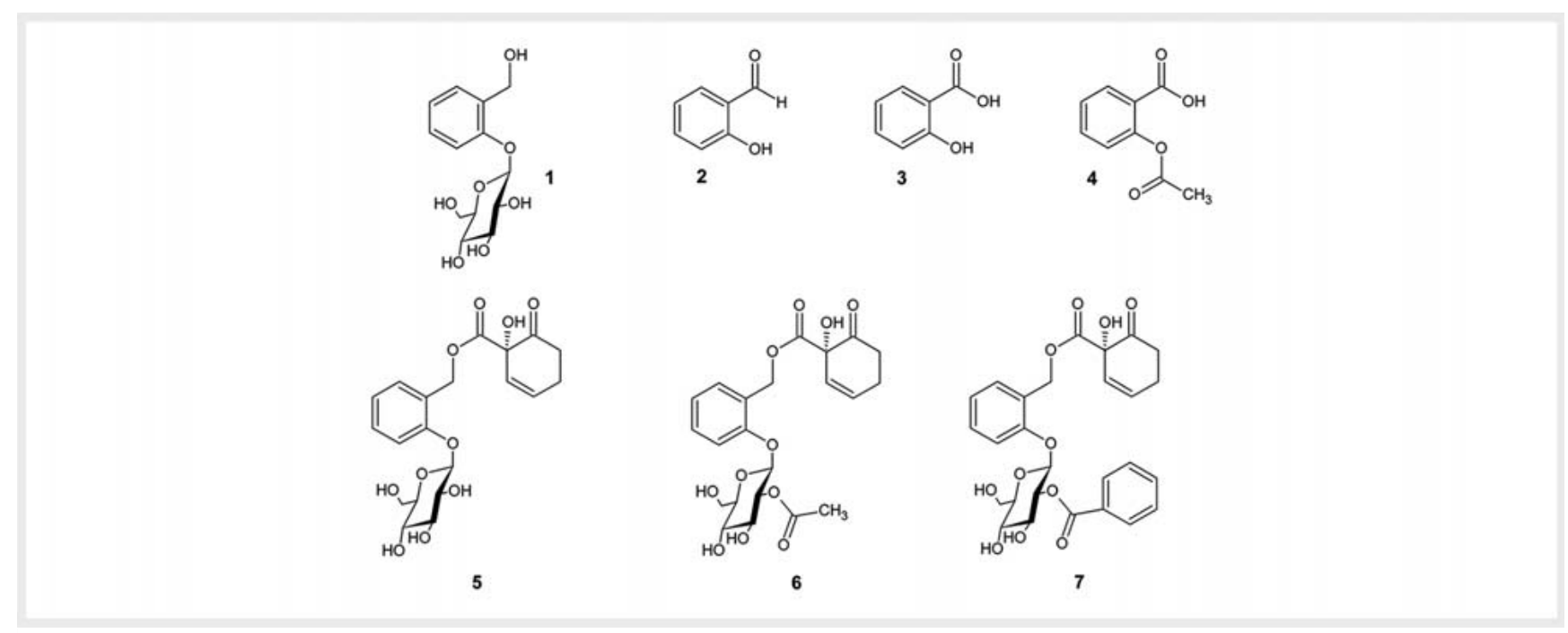

Fig. 3 Chemical structures of some salicylate derivatives found in willow bark: salicin (1); salicylaldehyde (2); salicylic acid (3); acetylsalicylic acid (4); salicortin (5); 2'-O-acetylsalicortin (6); (-)-tremulacin (7). 
- Table 1 Example of the lack of significant variation in willow bark phytochemical constituents in two high-salicylate species (data from [14-16]).

\begin{tabular}{|l|l|l|}
\hline Compound/Group of Compounds & Salix purpurea $\mathbf{L}$ & Salix daphnoides Vill. \\
\hline Total salicin (after hydrolysis) & $4-8 \%$ & $>4 \%$ \\
\hline Phenol glucosides including salicortin & up to $9 \%$ & $3-11 \%$ \\
\hline Tremulacin & rarely more than $1 \%$ & up to $1.5 \%$ \\
\hline Salireposide & $0.1-1.2 \%$ & $0.1-1.2 \%$ \\
\hline Syringin and purpurein & up to $0.4 \%$ & up to $0.2 \%$ \\
\hline Isosalipurposide & $0.15-2.2 \%$ & $0.2-1.5 \%$ \\
\hline Eriodictiol-7-glucoside & $0.18-0.4 \%$ & $0.3-1.5 \%$ \\
\hline$(+)$ and (-)-Naringenin-5-glucoside & $0.4-1.5 \%$ each & $0.3-1 \%$ each \\
\hline Total polyphenols & $5 \%$ & $5 \%$ \\
\hline$(+)$-Catechin & $0.5 \%$ of polyphenols & $0.5 \%$ of polyphenols \\
\hline
\end{tabular}

of Salix species, the $S$. daphnoides and S. daphnoides $\times$ purpurea hybrid species had the highest content of phenolic glycosides, while S. daphnoides had the highest content of flavonoids [14]. Some mechanistic studies have shown that catechins (flavan-3-ols) and other flavonoids may contribute to the anti-inflammatory effects of willow bark [21].

The USP quality monograph for willow bark defines willow bark (monograph titled: Salix Species Bark) as material prepared from the whole or fragmented dried bark of the young branches, or whole dried pieces of the current-year twigs, obtained from Salix species (family Salicaceae). The monograph mentions the following species as common in pharmacopeial use: Salix alba, S. babyIonica L., S. daphnoides, S. fragilis, S. chilensis Molina, S. pentandra L., and S. purpurea, and includes other complying willow species and their hybrids. Qualifying material contains not less than $1.50 \%$ of total salicylate derivatives, calculated as salicin $\left(\mathrm{C}_{13} \mathrm{H}_{18} \mathrm{O}_{7}\right)$ on the dried basis [22].

Other pharmacopeias and quality standards organizations have monographs for willow bark, e.g., the European Pharmacopoeia [23], European Medicines Agency [1], World Health Organization (WHO) [15], and European Scientific Cooperative on Phytotherapy (ESCOP) [24]. These monographs also specify a minimum of $1.5 \%$ of total salicylic derivatives, expressed as salicin.

\section{Salicylate Intakes from Dietary Supplements Containing Willow Bark}

Manufacturers of DSs formulate products with many combinations of botanical and/or non-botanical ingredients in proportions that vary widely. However, by examining product labels in the National Institute of Health (NIH) DSLD [25] and on the internet, we could estimate the general intake of salicylate in products containing willow bark. As of April 20, 2019, the DSLD contained labels of 217 DS products containing willow/Salix bark extract (with single or multiple ingredients), which recommend intake amounts in the range of 7.5 to $900 \mathrm{mg}$ of extract per day. The majority of products recommended less than $100 \mathrm{mg}$ extract per day. Of the three products that recommended higher intake lev- els, two products recommended $400 \mathrm{mg}$ extract twice daily with each intake delivering $120 \mathrm{mg}$ salicin, for a total of $240 \mathrm{mg}$ salicin per day. Another product recommended an intake level of $900 \mathrm{mg}$ per day of an extract standardized to $11 \%$ salicin, delivering approximately $100 \mathrm{mg}$ salicin per day. The DS manufacturers' recommended use information in the DSLD indicates that most DS products containing WBE deliver a wide range of salicin with a maximum of $240 \mathrm{mg}$ per day.

The WHO monograph for Cortex Salicis (which defines the ingredient as whole or fragmented dried bark from young branches of S. alba L., S. daphnoides Vill., S. fragilis L., S. purpurea L., and other appropriate Salix species (Salicaceae) recommends an adult oral daily dose of extracts, tinctures, or fluidextracts equivalent to $120-240 \mathrm{mg}$ of total salicin, or $6-12 \mathrm{~g}$ of powdered drug material as a decoction (boiled water based extract), which correspond to $120-240 \mathrm{mg}$ of total salicin, taken in two divided doses [15]. The European Medicines Agency (EMA) published a monograph for Salix cortex (various species including S. purpurea, S. daphnoides, and S. fragilis) and an herbal preparation(s) containing willow bark based on well-established and traditional uses. The EMA monograph sets a daily dose for WBE (DER of $8-14: 1,15 \%$ total salicin content) of 393 to $1572 \mathrm{mg}$ extract, corresponding to not more than $240 \mathrm{mg}$ salicin (single ingredient preparation) for a duration of not more than 4 weeks, for short-term treatment of LBP [1]. The ESCOP Monograph, British Herbal Compendium, German Commission E, and Health Canada monographs all recommend similar intake levels for dried hydroalcoholic or aqueous extracts, tincture or fluid extract, or bark powder delivering salicin levels equivalent to 120 to $240 \mathrm{mg}$ daily $[12,24,26,27]$.

\section{Regulatory Status of Willow Bark in the United States and Other Countries}

Willow bark is found in numerous DSs in the U.S. marketplace. Industry information suggests that willow bark was marketed in DSs prior to enactment of the Dietary Supplement Health and Education Act (DSHEA), and thus it may be considered an "old" dietary ingredient or a "grandfathered" dietary ingredient, able to be 
marketed without submission of a New Dietary Ingredient Notification (NDIN) to the U.S. Food and Drug Administration (FDA). Willow bark is included in the United Natural Products Alliance (UNPA) list of old dietary ingredients, a list that was compiled by DS manufacturers shortly after DSHEA came into force in 1994 [28]. Although the list is not recognized by the FDA as official or binding, it is well regarded as a reference tool in the DS industry.

In Canada, willow bark is recognized as a natural health product. The Natural Health Products Ingredients Database contains 19 entries for Salix [29]. As of August 2019, 324 natural health products (dosage forms) had been issued a license that is currently active [30].

In Europe, willow bark is an herbal medicine with well-established uses, as well as scientifically supported traditional uses. Similarly, in Australia, willow bark is a recognized medicine and as of April 2019, the Australian Register of Therapeutic Goods database contained 55 products, most of them multi-ingredient products that contain willow bark powder or extract [31].

Even with the varied regulatory status of willow bark in different countries, the recommended intake levels for use as a DS or as a medicine are very similar. The recommended intake levels deliver 120 to $240 \mathrm{mg}$ of salicin daily.

\section{Clinical Evidence of Safety}

A search of the public domain did not yield any clinical studies designed specifically to evaluate the safety of willow bark or willow bark extracts. Available clinical studies compared the effects of willow bark extracts on OA, rheumatoid arthritis, musculoskeletal disorders, and LBP with conventional medicines.

\section{Osteoarthritis and rheumatoid arthritis}

Biegert et al. [32] reported the outcome of two randomized, double-blind, controlled clinical trials of a standardized WBE corresponding to $240 \mathrm{mg}$ of salicin/day for treatment of OA or rheumatoid arthritis (RA). In the first study, the experimental design included a placebo washout phase of 4-10 days depending on the half-life of the analgesic or NSAID used previously. An exception was made to allow ongoing use of low-dose aspirin of up to $100 \mathrm{mg} /$ day. The OA trial involved 127 patients over 18 years of age with confirmed OA of the hip or knee according to the American College of Rheumatology (ACR) guidelines, with WOMAC [33] pain scores of at least 30 . They were divided into three groups: the willow bark group ( $n=43)$, a control group $(n=43)$, and a placebo group receiving tablets similar to the WBE $(n=41)$. The treatment phase duration was 6 weeks. The willow bark group received two coated tablets, twice daily, each tablet containing $393 \mathrm{mg}$ of a $70 \%$ ethanol extract of $S$. daphnoides with a DER of $8-14: 1$ containing approximately $60 \mathrm{mg}$ salicin (i.e., $240 \mathrm{mg}$ salicin/day). The positive control group received two enteric-coated tablets, twice daily, of diclofenac $25 \mathrm{mg}$ (i.e., $100 \mathrm{mg} /$ day), and the placebo group received two tablets, twice daily, of the placebo. No additional analgesics, NSAIDs, systemic, or intra-articular corticoids were allowed other than low-dose aspirin up to $100 \mathrm{mg}$ daily in all treatment groups. Physical therapy was allowed. The end point measured was the pain sub-score of the WOMAC OA index [33]. Only 106 of 127 patients completed the study and were included in the analysis. Lack of efficacy was the most common reason for withdrawal (five willow bark group, three diclofenac, and nine placebo); two patients in the diclofenac group withdrew due to AEs and two patients in the placebo group withdrew because they went on holiday abroad. Important protocol violations were committed by 17 patients: 10 (4 willow bark, 2 diclofenac, 4 placebo) had taken additional NSAID or analgesics (for reasons other than $\mathrm{OA}$ ) and 2 patients (both placebo) were considered noncompliant because they had taken less than $80 \%$ of the study medication. The willow bark group received significantly less physical therapy and reported decreased pain. The outcome was a somewhat decreased WOMAC score for the willow bark group, which was not significant when compared to placebo. Diclofenac effects were significant compared to placebo $(p=0.0002)$. A total of 173 AEs were reported. In the willow bark group, there were $38 \mathrm{AEs}$ in 19 patients compared to $51 \mathrm{AEs}$ in 20 patients in the placebo group, and 84 AEs in 30 patients in the diclofenac group. Most of the AEs involved the GI system and the central and peripheral nervous systems, accounting for more than $50 \%$ of the AEs in the placebo and diclofenac groups, but only approximately $30 \%$ in the willow bark group. The total number of AEs were significantly lower in the willow bark group compared to the diclofenac group [32].

The second RA study by Biegert et al. [32] involved 26 patients over 18 years of age, with confirmed RA. Participants were divided into a treatment and a placebo group ( $n=13$ each). The treatment group received two coated tablets, twice daily, containing $393 \mathrm{mg}$ of the same WBE described above, delivering $240 \mathrm{mg}$ salicin/day for 6 weeks. NSAIDs and analgesics were discontinued other than $100 \mathrm{mg}$ aspirin/day, which was allowed. The end point was a change in pain using the Visual Analog Scale (VAS) [34]. At the end of the trial, the estimation of pain by the VAS decreased for the willow bark group, but not significantly. A total of $14 \mathrm{AEs}$ were reported ( 7 in each group), but data on the nature of the observed effects were not provided. The authors reported that none of the AEs were serious and causality was assessed as "possible" for only two AEs in the placebo group and only one $A E$ in the WBE group [32].

In conclusion, the authors found no evidence for a relevant analgesic or anti-inflammatory efficacy of the investigated WBE in either of patients with OA or RA. A power estimate of the study showed that a true difference in pain reduction between WBE and placebo of $15 \mathrm{~mm}$ (suggested as the minimum clinically relevant difference) or more can be excluded with a probability of $93 \%$. A difference of $10 \mathrm{~mm}$ or more can be excluded with a probability of $83 \%$ [32]. However, the permitted ongoing use of low-dose aspirin at up to $100 \mathrm{mg} /$ day may have confounded the results.

An open, descriptive, observational study by Saller et al. [35] involved 877 patients with different types of rheumatic pain (OA, RA, LBP, soft tissue disorders). The study duration was 6-8 weeks, with an intermediate control visit after 3-4 weeks. They evaluated the frequency of adverse drug reactions and efficacy of a proprietary willow bark extract. The WBE was standardized to $15.2 \%$ salicin, providing $60 \mathrm{mg}$ of salicin per tablet, and was given at doses of 1-2 tablets per day or 3-4 tablets per day for $6-8$ weeks. The dosage of the WBE given depended on the physician's judgement of the patient's needs, e.g., the severity of the condition being 
treated and whether or not concomitant medications for that condition were being administered. Since this was an observational study, there was only the one study group and analyses by condition and treatment were done post hoc. When needed, anti-inflammatory drugs were used (39.3\% of the cases). Pain intensity was assessed, and data was compared with the corresponding baseline values. The results showed a tendency of decreased pain scores in the willow bark-treated patients, but the change was not significant compared to baseline. A total of 38 patients $(4.3 \%)$ reported 46 adverse drug reactions that were related to the $\mathrm{Gl}(3.1 \%)$ and skin (1.6\%), but none were classified as serious. The lack of a control group was a weakness of the study [35].

Another randomized, double-blind, placebo-controlled trial by Schmidt et al. [36] compared the effects of WBE and placebo on $\mathrm{OA}$. Patients with confirmed OA were randomized to receive either placebo $(n=39)$ or WBE $(n=39)$. After a washout period of 4-6 days (day -4 to day 0 ), participants were administered either placebo or two tablets WBE twice daily for 2 weeks. The WBE was standardized to $17.6 \%$ salicin and each coated tablet contained $340 \mathrm{mg}$ extract of willow bark, delivering $120 \mathrm{mg}$ salicin $(240 \mathrm{mg}$ salicin daily). The placebo was made up of cellulose and lactose. No other medications or analgesics were allowed during the study. Patients were assessed on days $-4,0,7$, and 14 to determine the WOMAC OA index. Blood and urine samples were obtained for standard laboratory tests and patients recorded any AEs. The group treated with WBE reported a moderate relief with a $14 \%$ reduction in WOMAC score versus $2 \%$ increase in the placebo, thus a significant $(p=0.047)$ reduction in pain compared with placebo [36]. A total of five patients reported AEs; four patients ( 1 in active treatment group, 3 placebo group) dropped out because they needed additional analgesics for pain and one patient in the active treatment group had an allergic reaction and dropped out after 14 days. Ten patients were excluded from analysis because they violated the protocol as follows: had electrotherapy during study protocol (three placebo, five active treatment), one placebo patient had baseline WOMAC index taken on day 2 (instead of day 0 ), and one active treatment patient underwent only a 1 -day washout phase (instead of 4 days). The number of patients reporting AEs was the same in both groups at 16 each, but the total number of AEs was higher in the placebo group $(n=28)$ compared to the willow bark group $(n=17)$. The results of hematology, clinical chemistry, and urinalysis measured at day - 4 versus at termination showed significant differences between the groups as follows: white blood cell counts (treatment: $0.6 \times 10^{3} / \mu \mathrm{L}$; placebo: $0.01 \times 10^{3} / \mu \mathrm{L}$ ), serum glutamic oxaloacetic transaminase (active treatment: $0.26 \mathrm{U} / \mathrm{L}$; placebo: $0.94 \mathrm{U} / \mathrm{L}$ ), and glucose in serum (treatment: $3.76 \mathrm{mg} / \mathrm{dL}$; placebo: $11.03 \mathrm{mg} / \mathrm{dL}$ ). None of the changes were considered clinically relevant, as the mean values were within normal ranges [36].

\section{Musculoskeletal disorders}

Uehleke et al. [37] examined the efficacy and safety of willow bark aqueous extract for pain reduction in a pragmatic surveillance study (non-interventional) of 436 patients suffering from MSDs, OA (56.2\%) and back pain (59.9\%). Aqueous WBE (STW 33-I) delivering $120 \mathrm{mg}$ salicin per tablet (with a DER of 16-23:1) was ad- ministered (two tablets daily; $240 \mathrm{mg} /$ day salicin) to all patients, who were also allowed co-medication with NSAIDs, mostly diclofenac or ibuprofen, and/or opioids. Treatment regimens consisted of STW 33-1 alone ( $n=268)$, STW 33-1 + NSAIDs ( $n=126)$, STW 33-1 + NSAIDs + opioids $(n=17)$, and STW 33-1 + NSAIDs + opioids + other medications $(n=25)$. Patients were monitored at baseline and after 3, 6, 12, 18, and 24 weeks. Evaluation was done using an extensive case report form and pain questionnaires, and patients were asked to track their pain levels and AEs in a diary. A total of $36.5 \%$ of participants dropped out of the study due to lack of treatment efficacy as follows: (11.2\% in the STW 33-1 monotherapy group, $19 \%$ in STW 33-I + NSAIDs, $23.5 \%$ in STW 33-1 + NSAIDs + opioids, and $40 \%$ in the group receiving other medication). While there were fewer dropouts in the group that received only the STW 33-1, this data was not analyzed statistically. The higher dropout rates of patients using combination therapies would need to be evaluated further to clarify if it was triggered due to a lack of analgesia in more severe pain conditions. A possible implication is that patients with mild and chronic pain conditions could be treated with willow bark alone. There were $106 \mathrm{pa}$ tient reports of AEs of which 7 were described as serious, but details of the AEs were not provided and information on patient groups were not provided. There was a total of 176 AEs of which $63(35.8 \%)$ occurred in patients using STW 33-1 only, 96 (54.5\%) in the STW 33-1 + NSAIDs, and 17 (9.7\%) in the STW 33-1 + NSAIDs + opioids. The AE groups could be categorized into the following system organ classes (SOC): Gl disorders ( $n=45$, e.g., upper abdominal pain, nausea, gastric disorder, dyspepsia), general disorders ( $n=17$, e.g., influenza-like illness, pain, fatigue), infections and infestations ( $n=17$, e.g., Gl infection, viral infection), and musculoskeletal and connective tissue disorders ( $n=13$, e.g., arthralgia, sciatica). The most commonly involved SOC was $\mathrm{Gl}$, although it is not clear whether a specific treatment group was more affected than others. The authors reported that the outcome was a significant reduction in pain and concluded that the treatment showed good tolerability considering the reduction in pain in relation to the $\mathrm{AEs}$ and no relevant drug interactions were observed [37].

Beer and Wegener [38] conducted an open label, multicenter, prospective observational study comparing efficacy and tolerability of treatment of gonarthrosis and coxarthrosis with a standardized WBE versus reference (conventional) treatment. Some of the physicians' choice of drugs included coxibe, diclofenac, ibuprofen, and oxicame - this was not a control group, instead treatment was based on the physicians' professional judgement. The WBE was Optovit actiFLEX made from Salicis cortex Ph. Eur., DER 8-14: 1 , ethanol $70 \% \mathrm{v} / \mathrm{v}$, with each tablet containing $393.24 \mathrm{mg}$ dry WBE and therefore $60 \mathrm{mg}$ salicin. Patients were administered 786.48 to $1572.96 \mathrm{mg}$ WBE/day, equivalent to $120-240 \mathrm{mg}$ salicin/day, taken in divided doses for 6 weeks. Patients were examined at baseline and at 3 and 6 weeks by clinical findings, AEs, global tolerance, and WOMAC questionnaires (concerning pain and stiffness, questions on general state of health). Three patients dropped out of the study: one in the WBE group with no reason given, one in the WBE group for poor tolerance, and one in the reference treatment group for poor tolerance. Data from the remaining subjects in the WBE treatment group $(n=88)$ and refer- 
ence treatment group $(n=40)$ were analyzed. Fourteen non-serious AEs were reported in the following groups: WBE $(n=1)$, reference treatment group ( $n=11), 2$ additional AEs occurred among the 8 patients who received a combination of WBE and conventional drugs. Of these AEs, only two were categorized as drug reactions, specifically reflux, which occurred only in the reference treatment and combination groups. The authors concluded that WBE was better tolerated than the reference medication, and both patients and doctors considered the effects of WBE comparable to the other analgesics. By the end of the study, WBE demonstrated a slightly better trend in relieving pain and improving quality of life, and no serious AEs were observed [38].

\section{Low back pain}

Chrubasik et al. [39] conducted a randomized, double-blind, 3armed clinical trial [40]. Participants who had at least 6 months of intermittent LBP were divided into 3 equal groups ( $n=70$ each) who were administered graded doses of either WBE or placebo for 4 weeks. Patients received daily doses of $786 \mathrm{mg}$ dry WBE (equivalent to $120 \mathrm{mg}$ salicin) or $1572 \mathrm{mg}$ dry standardized WBE with $15 \%$ salicin (70\% ethanol extract, DER $8-14: 1$, equivalent to $240 \mathrm{mg}$ salicin), taken in two divided doses daily for 4 weeks. Patients were permitted to take tramadol as a rescue medication when needed. Participants' pain characteristics were similar in the three groups [e.g., radiation into leg(s), neurological signs], except that the high-dose salicin group had greater invalidity, physical impairment, and overall Arhus LBP and Beck depression scores. Success of the treatment was measured by the number of patients that did not need tramadol for at least 5 days in the final week of the study. The secondary outcome was a change in the modified Arhus score compared to baseline (i.e., the percentage of patients who required tramadol). The results showed a dosedependent analgesic effect in patients who were treated with WBE. The proportion of patients who showed improved pain scores were as follows: 4 of 59 (6\%) patients in placebo, 15 of 67 (21\%) in the low-dose group, and 27 of 65 (39\%) in the high-dose willow bark group $(p<0.001)$. Patients in the placebo group required much more rescue medication. One patient in the lowdose willow bark (120 mg salicin) treatment group suffered a severe allergic reaction (exanthema, pruritis, swollen eyes). The symptoms resolved 2 days after the patient stopped treatment, indicating the event may have been attributable to the treatment. Two patients in the high-dose group $(240 \mathrm{mg}$ salicin treatment group) had short-lasting AEs: one had dizziness attributed by the investigators to tramadol, the other had dizziness and fatigue; both dropped out, one for insufficient pain relief and the other for unspecified reasons. The AEs reported by six patients in the placebo group were mild. In three cases, the patients attributed them to the tramadol (dizziness/headache, dizziness/vomiting/ diarrhea, dry mouth). The remaining three patients suffered from mild abdominal pain with or without diarrhea. Two of these patients discontinued the study on the first day of treatment [40].

Another study by Chrubasik et al. [39] was an open-label, randomized, active-controlled clinical trial with 2 arms to evaluate the effects of WBE in 228 patients with at least 6 months of nonspecific LBP. Patients were randomly allocated to 2 groups of 114 participants each and assigned to receive either a daily dose of
1572 mg standardized WBE (as 4 capsules containing 70\% ethanol extract, 8-14:1 DER, 15\% salicin delivering $240 \mathrm{mg}$ salicin per day) or $12.5 \mathrm{mg}$ rofecoxib ( 1 single tablet per day) for 4 weeks. Patients were allowed free access to conventional treatments (any medication they usually used in the event of severe pain, in addition to NSAIDs, acupuncture, and physical therapy when needed). The primary outcome was pain measured on a modified Arhus index (pain component and TPI) [41], physician- and patient-rated success, and the acceptability of the treatment communicated verbally by patients. Irrespective of treatment group, after 4 weeks of treatment, the VAS for pain score had improved by about $44 \%$, the modified Arhus index had improved by $20 \%$, its pain component decreased by $30 \%$, and the TPI decreased by $35 \%$ in both groups. The number of patients with a VAS score below 2 (considered to be pain free) at the end of 4 weeks was 22 in the WBE group and 20 in the NSAID group. No significant difference was observed between the two groups in pain scores. AEs reported in the willow bark group (and the authors' causality judgment in parentheses) were as follows: allergy ( 1 possible, 3 likely, 1 clear connection), GI, dyspepsia, vomiting, heartburn, diarrhea (7 possible, 3 likely, 1 clear connection), dizziness (1 possible), headache (1 possible), and blood pressure instability (1 possible). The rofecoxib group reported $27 \mathrm{AEs}$, which included asthma, dyspepsia, nausea, diarrhea, heartburn, ulcer, GI bleeding, dizziness, headache, and edema [39].

Taken together, the clinical trials reviewed here [32, 35-40] administered WBE that was prepared with $70 \%$ ethanol (DER of $8-$ $14: 1$ ) and contained approximately $15 \%$ salicin, delivering 120 to $240 \mathrm{mg}$ salicin per day for up to 8 weeks. In most cases, dosage forms were prepared as coated tablets and administered in two divided doses per day. No serious AEs were reported. The most common mild AEs observed were Gl effects and allergic reactions. All studies involved adult patients, no studies involved persons under 18 years of age, or persons in special populations such as pregnant or breastfeeding women.

\section{Animal Toxicology}

There was a dearth of information from animal studies on the toxicity of willow bark, although there were a number of studies that addressed the mechanism(s) of action of the extract. A hydroethanolic (30\%) extract of willow bark had an $L_{50}$ of $28 \mathrm{~mL} / \mathrm{kg}$ when administered to mice. In one case, the administration of a single dose of $5 \mathrm{mmol} / \mathrm{kg}$ salicin to rats caused no gastric injury, while saligenin (a metabolite of salicin) and sodium salicylate induced severe gastric lesions [42].

\section{Pharmacokinetics of Salicin, Potential Effects on Platelet Aggregation, and Drug Interactions}

Although salicin is believed to be the major active compound in willow bark and is a prodrug metabolized to saligenin in the $\mathrm{Gl}$ tract and then to salicylic acid after absorption [43], it has also been proposed that other components of willow bark may contribute to its therapeutic effects $[18,44]$ 
A clinical study by Schmid et al. [44] demonstrated that the ingestion of WBE delivering $240 \mathrm{mg}$ salicin (1360 mg extract) in divided doses ( 2 tablets at $0 \mathrm{~h}$ and another 2 tablets $3 \mathrm{~h}$ later) resulted in an area under the curve equivalent to that expected from an intake of $87 \mathrm{mg}$ acetylsalicylic acid. The bioavailability was $43.3 \%$, peak serum levels were $1.2 \mathrm{mg} / \mathrm{L}$, and both were reached within $2 \mathrm{~h}$ after ingestion. Renal elimination of salicin is predominantly in the form of salicyluric acid (71\% of total salicylates), followed by salicylic acid (15\%) and gentisic acid (14\%). Neither saligenin nor salicin were detected in serum or urine. After $24 \mathrm{~h}$, on average $15.8 \%$ of the orally ingested dose of salicin was detected in the urine as salicylates.

An in vivo study in rats compared the oral administration of salicin $(400 \mathrm{mg} / \mathrm{kg})$ to sodium salicylate $(29 \mathrm{mg} / \mathrm{kg})$. In the case of salicin, salicylic acid appeared slowly, with a $C_{\max }$ of $82.4 \mu \mathrm{g} / \mathrm{mL}$ after $5 \mathrm{~h}$. With sodium salicylate, salicylic acid appeared more rapidly, with a $C_{\max }$ of $104.2 \mu \mathrm{g} / \mathrm{mL}$ at $1.5 \mathrm{~h}$. The relative bioavailability of salicylic acid from salicin was only $3.25 \%$ compared to sodium salicylate [45] and its elimination was slower. Akao et al. [42] also demonstrated that the absorption of salicin is slower compared to saligenin or salicylic acid.

In another study, salicylates or aspirin was administered to rats at a dose of $200 \mathrm{mg} / \mathrm{kg}$. The results showed that salicylate was not an effective inhibitor of platelet aggregation, as it had a much weaker effect than aspirin on thromboxane B2 production in blood clotting [46].

Concern has been raised regarding the potential for willow bark to inhibit platelet aggregation, an issue investigated by Krivoy et al. [47]. In a double-blind, placebo-controlled study, 35 patients with acute LBP were administered either WBE $(n=19)$ or placebo $(n=16)$ for 28 days, and a further 16 patients with stable chronic ischemic heart disease were given $100 \mathrm{mg}$ ASA per day. The WBE "Assalix" was made with S. daphnoides and S. purpurea and delivered $240 \mathrm{mg}$ salicin per day. Platelet aggregation was measured after 28 days of treatment. There were significant differences between the placebo and the willow bark-treated groups in the maximal platelet aggregation induced with arachidonic acid $(p=0.04)$ and adenosine diphosphate $(p=0.01)$. No statistical difference was found between the groups when collagen was applied to human platelets. While ASA had a significantly greater inhibitory effect on platelet aggregation compared to WBE $(p=0.001)$ and placebo $(p=0.001)$, further investigation is needed to clarify if this finding is of clinical relevance in patients with impaired thrombocyte function.

Shalansky et al. [48] carried out a prospective longitudinal study in 171 adults to determine the risk of bleeding and supratherapeutic international normalized ratios (INR) associated with the use of complementary and alternative medicine (CAM) in patients receiving warfarin. Statistically significant associations between the use of willow bark and bleeding events were observed. The risk of a supratherapeutic INR was not increased. After adjustment for identified non-CAM risk factors, the association was not statistically significant.

The WHO monograph for Cortex Salicis cautions against the use of willow bark in children under 12 years of age, citing the possibility of Reye (sometimes spelled Reye's) syndrome (sudden acute brain and liver damage that has been associated with the use of aspirin). The monograph also contraindicates the use of willow bark in patients with hypersensitivity to other nonsteroidal anti-inflammatory drugs and in people with asthma because of potential severe reactions (acute bronchospasms). This contraindication is maintained in the 2017 review carried out by EMA [1].

The American Herbal Products Association's (AHPA) Botanical Safety Handbook classifies Salix spp. bark as an herb that can be safely consumed when used appropriately, however, caution is advised because of the risk of increased bleeding and the fact that salicylates cross the placenta and that newborns eliminate them very slowly [49].

\section{Adverse Events Associated with Intake of Willow Bark}

In the clinical studies reviewed herein, no serious AEs were reported. The most common mild AEs observed involved the GI tract. All studies involved adult patients, no studies involved persons under 18 years of age or persons in special populations such as pregnant or breastfeeding women. However, some rare but potentially serious AEs have been reported in case reports associated with the use of willow bark.

A case of allergic reaction was reported in a carpenter who developed a widespread rash when working with willow wood, similar to what he had previously experienced with aspirin [50].

A case of anaphylactic reaction was reported in a 25-year-old woman with asthma who had a previously known allergy to aspirin. Within 75 min of ingesting a DS containing WBE, the patient developed an anaphylactic reaction. The patient was successfully treated with epinephrine, diphenhydramine, and a corticosteroid. No analysis was done on the product to confirm its contents. In the absence of other contributing factors, the authors considered willow bark to likely be responsible for the adverse effects based on the Naranjo probability scale [51].

Acute respiratory syndrome was reported in a 61-year-old female with a past medical history of hypertension and osteoarthritis after taking a DS containing white willow bark. She presented with a sudden onset of shortness of breath and a nonproductive cough. The patient denied any history of drug or supplement allergy and was successfully treated with intravenous methylprednisolone, oral diphenhydramine, and ranitidine [52].

A massive intravascular hemolysis was reported in a woman with glucose-6-phosphate dehydrogenase (G6PD) deficiency who had taken an Ayurvedic herbal product containing Salix caprea, a willow species containing salicin [53]. The patient consumed $5 \mathrm{~mL}$ of a multi-ingredient formulation. No additional information was available. The authors assigned causality to S. caprea because of its salicin content and the knowledge that in patients with G6PD deficiency, aspirin can cause hemolytic anemia [54].

A recent case reported fatal fulminant hepatic failure (FHF) in a 28-month-old male infant following treatment with acetaminophen and a traditional aboriginal medicine ("Lake Twig tea"). The herbal medicine contained willow bark; however, according to the author, the nature of the product was unclear and may have contained leaf material. The authors ruled out acetaminophen as the sole causal agent because blood chemistry test results indicated 
low levels of acetaminophen and serum aspirin levels below the toxic range. Although the clinical history and course of disease appeared to suggest classic Reye syndrome, and the autopsy indicated diffuse microvesicular steatosis typical of Reye syndrome, there was centrilobular necrosis that is more typical of drug-induced liver injury due to acetaminophen. The authors concluded that the FHF was a result of toxic synergism between acetaminophen and ASA, which may have been due to salicylates in the willow bark [55].

\section{Heavy Metals in Willow Bark}

A risk assessment carried out by European Food Safety Authority (EFSA) on white willow in food concluded that its heavy metal content, specifically cadmium, may present a risk to health and should be further evaluated [56]. A number of studies have shown that willow species tend to accumulate heavy metals, specifically zinc and cadmium, and for this reason have been used for phytoremediation in polluted sites in some countries in Europe [57-59]. Studies have shown that heavy metals transfer from the bark into the extracts during manufacturing of extracts. However, compliance with pharmacopeial limits for elemental impurities would mitigate that risk. Herbal products containing willow bark in the European market were shown to have higher levels of cadmium, with the calculated 90 th percentile for samples calculated to contain 2.74 ppm, thus supporting a higher cadmium limit in the European Pharmacopoeia monographs for Willow Bark at NMT $2.0 \mathrm{ppm}[23,60]$ compared to the limit of $1.0 \mathrm{ppm}$ in the European Pharmacopoeia general monograph for Herbal drugs [61].

\section{Concluding Remarks}

This review found that although willow bark has been used for millennia, there are limited data on its safety. Most published clinical trials [32, 36-39] involved administration of WBEs in coated tablet form that delivered $120-240 \mathrm{mg}$ salicin per day, taken in divided doses, for up to 8 weeks. No serious AEs were reported in the published clinical trials. The most common mild AEs included $\mathrm{Gl}$ effects (e.g., upper abdominal pain, nausea, gastric disorder, and dyspepsia), which did not lead to the discontinuation of any study. All studies involved adult patients. No studies or reports have examined the effects of use of WBEs during pregnancy and lactation. The AHPA Botanical Safety Handbook classifies Salix spp. Bark as an herb that can be safely consumed when used appropriately, however, caution is advised because of the risk of increased bleeding and the fact that salicylates cross the placenta and newborns eliminate them very slowly [49]. Several allergic reactions, including one serious case of anaphylaxis, were described in case reports, similar to what patients had experienced with aspirin following ingestion of WBE [53]. Because Salix spp. contain salicylates, concurrent use with aspirin and other salicylate-containing drugs, as well as use by persons with sensitivity to aspirin or other salicylate-containing drugs, is cautioned. At least one case report exists of a woman with G6PD deficiency who experienced lifethreatening hemolysis after ingesting a herbal product containing S. caprea [53]. One case of FHF was recently reported in an infant who had been given willow bark and acetaminophen. The authors concluded that the hepatic failure was the result of toxic synergism between acetaminophen and salicylates from the willow bark tea.

This review found no serious AEs associated with the ingestion of willow bark powder or aqueous or hydroalcoholic extracts of willow bark at levels of intake higher than those recommended on DS labels listed in the DSLD (i.e., 7.5 to $900 \mathrm{mg}$ of extract/ day). The majority of products have recommended intakes of less than $100 \mathrm{mg}$ extract per day. Thus, DS products containing WBEs delivering salicin at less than the maximum amounts used in clinical trials are not likely to cause serious adverse effects, except in individuals who may be sensitive or allergic to components of willow bark. Serious AEs have been reported in individuals with a sensitivity/allergy to aspirin and in one case report of an individual with G6PD deficiency.

DS products containing willow bark deliver up to $240 \mathrm{mg}$ of salicin, which can be metabolized into $113 \mathrm{mg}$ salicylic acid among other metabolites. However, when sold as DSs, these products are not required to bear any label warning. In contrast, over-thecounter (OTC) low-dose aspirin (81 mg strength) delivering $62 \mathrm{mg}$ of salicylic acid is required to include guidelines on the use in pregnant women and children, as well as contraindications pertaining to blood coagulation. In the interest of protecting public health, the USP Dietary Supplements Admission Evaluations Joint Standard Setting Subcommittee directed that a cautionary labeling statement be included in the USP Salix Species monograph that reads as follows: "Dosage forms prepared with this article should bear the following statement: "Not for use in children, women who are pregnant or nursing, or by persons with known sensitivity to aspirin'” [22].

The term "known sensitivity to aspirin" is intended to alert consumers that they should not consume WBEs if they are already avoiding aspirin because their doctor has told them that one or more of the cautions, warnings, and contraindications provided on the label of aspirin products apply to them. Aspirin is a wellknown drug and patients at risk receive detailed warnings from their doctor and clear information from the extensive cautionary labeling on aspirin packages and package inserts. Thus, this approach to cautionary labeling for WBEs is considered to be consistent with the scientific evidence indicating lower but not absent risks. It is also more practical for manufacturers of DSs who declare compliance with USP standards than expecting them to duplicate the extensive cautionary labeling of OTC drugs.

\section{Recommendations for Further Research}

Based on the literature reviewed in this paper, some recommendations can be made for research to clarify current uncertainties. Although it is believed that the salicylates are partly responsible for the analgesic effects, the specific phytochemical constituent (s) or combinations thereof that are responsible for the biological activity of willow bark are unclear. Research to clarify the roles of the various constituents is required. In addition, there is a paucity of preclinical data related to the safety of willow bark and its constituents. It is recommended that further preclinical work (in vitro and in vivo toxicology studies) be conducted to further inform about the safety of willow bark and its constituents. 


\section{Acknowledgements}

The authors wish to thank the members of the 2015-2020 USP Dietary Supplements Admission Evaluations Joint Standard Setting Subcommittee (USP DS AE JS3) for valuable discussions of the review, colleagues at USP: Dr. Jaap Venema, Alissa Jijon JD, and Dr. Emily Madden, for critically reviewing the manuscript, and Ms. Eleonora d'Amore (USP) for copyediting the manuscript. We thank Mr. Thomas Brendler for providing some of the photographs of willow bark ( $\vee$ Fig. 1 A, C, D).

\section{Conflict of Interest}

The authors declare they have no conflict of interest.

\section{References}

[1] European Medicines Agency (EMA)-Committee on Herbal Medicinal Products (HMPC). Assessment report on Salix [various species including S. purpurea L., S. daphnoides Vill., S. fragilis L.], corte. Available at https:// www.ema.europa.eu/en/documents/herbal-report/final-assessmentreport-salix-various-species-including-s-purpurea-l-s-daphnoides-vill-sfragilis-I_en.pdf. Accessed: August 19, 2019

[2] Applequist W. The identification of medicinal plants: a handbook of the morphology of botanicals in commerce. St. Louis: Missouri Botanical Garden Press; 2007

[3] Wood JN. From plant extract to molecular panacea: a commentary on Stone (1763) 'An account of the success of the bark of the willow in the cure of the agues'. Philos Trans R Soc Lond B Biol Sci 2015; 370 : 20140317

[4] Mahdi JG. Medicinal potential of willow: A chemical perspective of aspirin discovery. J Saudi Chem Soc 2010; 14: 317-322

[5] Mahdi JG, Mahdi AJ, Bowen ID. The historical analysis of aspirin discovery, its relation to the willow tree and antiproliferative and anticancer potential. Cell Prolif 2006; 39: 147-155

[6] Authorities of the Medical Societies and Colleges. The Pharmacopoeia of the United States of America. Boston, MA: Wells and Lilly; 1820

[7] Shara M, Stohs SJ. Efficacy and safety of white willow bark (Salix alba) extracts. Phytother Res 2015; 29: 1112-1116

[8] Oketch-Rabah HA, Roe AL, Muldoon-Jacobs K, Giancaspro Gl. Challenges and opportunities for improving the safety assessment of botanical dietary supplements: a united states pharmacopeia perspective. Clin Pharmacol Ther 2018; 104: 426-429

[9] USP. Guideline for the Admission of Dietary Supplement Ingredients to the USP-NF Monograph Development Process. Available at https:// www.usp.org/sites/default/files/usp/document/get-involved/ submission-guidelines/guideline-for-the-admission-of-dietarysupplement-ingredients.pdf. Accessed: August 19, 2019

[10] USP. Sample USP-NF monograph. Available at https://www.uspnf.com/ sites/default/files/usp_pdf/EN/USPNF/sample_monograph.pdf. Accessed: August 19, 2019

[11] USP. Reference Standards. Available at https://www.usp.org/referencestandards. Accessed: August 19, 2019

[12] Bradley PR. British Herbal Compendium, Volume 1. A Handbook of Scientific Information on Widely Used Plant Drugs. Companion to Volume 1 of the British Herbal Pharmacopoeia. Bournemouth, Dorset: British Herbal Medicine Association; 1992

[13] Wichtl M. Herbal Drugs and Phytopharmaceuticals: A Handbook for Practice on a Scientific Basis. Stuttgart: CRC Press; 2004

[14] Gawlik-Dziki U, Sugier D, Dziki D, Sugier P. Bioaccessibility in vitro of nutraceuticals from bark of selected Salix species. ScientificWorldjournal 2014; 2014: 782763
[15] WHO. Cortex Salicis. In: Volume 4. WHO Monographs on Selected Medicinal Plants. Geneva, Switzerland: WHO; 2009

[16] Förster N, Ulrichs C, Zander M, Kätzel R, Mewis I. Influence of the season on the salicylate and phenolic glycoside contents in the bark of Salix daphnoides, Salix pentandra, and Salix purpurea. J Appl Bot Food Qual 2012; 82: 99-102

[17] Noleto-Dias C, Ward JL, Bellisai A, Lomax C, Beale MH. Salicin-7-sulfate: A new salicinoid from willow and implications for herbal medicine. Fitoterapia 2018; 127: 166-172

[18] Nahrstedt A, Schmidt M, Jaggi R, Metz J, Khayyal MT. Willow bark extract: the contribution of polyphenols to the overall effect. Wien Med Wochenschr 2007; 157: 348-351

[19] Shao Y. Phytochemischer Atlas der Schweizer Weiden. Diss. Naturwiss.: ETH Zurich; 1991: Nr. 9532

[20] Jurgenliemk G, Petereit F, Nahrstedt A. Flavan-3-ols and procyanidins from the bark of Salix purpurea L. Pharmazie 2007; 62: 231-234

[21] Freischmidt A, Jurgenliemk G, Kraus B, Okpanyi SN, Muller J, Kelber O, Weiser D, Heilmann J. Contribution of flavonoids and catechol to the reduction of ICAM- 1 expression in endothelial cells by a standardised Willow bark extract. Phytomedicine 2012; 19: 245-252

[22] United States Pharmacopeia (USP). Salix Species Bark. In: USP42-NF37. Rockville, MD: United States Pharmacopeia (USP); 2019: 5185

[23] European Pharmacopoeia (Ph. Eur.). Willow bark (Salicis Cortex), Willow Bark Dry Extract (Salicis Corticis Extracum Siccum). In: 9th Edition 2019 (9.8). European Pharmacopoeia (Ph Eur). Strasbourg, France: The European Directorate for the Quality of Medicines \& HealthCare; 2019: 1561-1562

[24] ESCOP (European Scientific Cooperative on Phytotherapy). ESCOP Monographs: Salicis cortex, Willow Bark, Salix spp. including S. purpurea L., S. daphnoides Vill. and S. fragilis L. 2017. Available at http://escop. com. Accessed: August 19, 2019

[25] National Institutes of Health (NIH). Dietary Supplement Label Database. In: Version 7.0.7 - May 2019 (5a1ad7d). Bethesda, MD: Office of Dietary Supplements and National Library of Medicine; 2019.

[26] Canada H. Willow Bark Natural Health Product Monograph. October 18, 2013. Available at http://webprod.hc-sc.gc.ca/nhpid-bdipsn/atReq.do? atid=white.wil.saule.bla\&lang=eng. Accessed August 23, 2019

[27] Blumenthal M, Goldberg A, Brinckmann J. Herbal Medicine. Expanded Commission E monographs: Integrative Medicine Communications; 2000. Newton, MA

[28] United Natural products Alliance (UNPA). Old Dietary Ingredient List. Available at http://dnndvlduk.cloudapp.net/Portals/0/Documents/News/ UNPA_ODI_List\%207-23-08.pdf. Accessed: August 19, 2019

[29] Canada H. Natural Health Products Ingredients Database. 2019. Available at http://webprod.hc-sc.gc.ca/nhpid-bdipsn/search-rechercheReq. do?lang=eng. Accessed: August 23, 2019

[30] Canada H. Licensed Natural Health Products Database. 2019. Available at https://health-products.canada.ca/Inhpd-bdpsnh/index-eng.jsp. Accessed: August 22, 2019

[31] Government A. Australian Register of Therapeutic Goods. 2019. Available at https://www.tga.gov.au/artg. Accessed: August 22, 2019

[32] Biegert C, Wagner I, Ludtke R, Kotter I, Lohmuller C, Gunaydin I, Taxis K, Heide L. Efficacy and safety of willow bark extract in the treatment of osteoarthritis and rheumatoid arthritis: results of 2 randomized doubleblind controlled trials. J Rheumatol 2004; 31: 2121-2130

[33] WOMAC. Western Ontario and McMaster Universities Arthritis Index (WOMAC). Available at https://web.archive.org/web/20180815012621/ http://www.womac.org:80/womac/index.htm. Accessed: August 19, 2019

[34] Crichton N. Visual analogue scale (VAS). J Clin Nurs 2001; 10: 706 
[35] Saller R, Melzer ], Felder M, Group SAS. Pain relief with a proprietary extract of Willow Bark in rheumatology. An open trial. Schweizerische Zeitschrift fur GanzheitsMedizin 2008; 20: 156

[36] Schmidt B, Ludtke R, Selbmann HK, Kotter I, Tschirdewahn B, Schaffner W, Heide L. Efficacy and tolerability of a standardized willow bark extract in patients with osteoarthritis: randomized placebo-controlled, double blind clinical trial. Phytother Res 2001; 15: 344-350

[37] Uehleke B, Muller ], Stange R, Kelber O, Melzer ]. Willow bark extract STW $33-1$ in the long-term treatment of outpatients with rheumatic pain mainly osteoarthritis or back pain. Phytomedicine 2013; 20: 980-984

[38] Beer AM, Wegener T. Willow bark extract (Salicis cortex) for gonarthrosis and coxarthrosis-results of a cohort study with a control group. Phytomedicine 2008; 15: 907-913

[39] Chrubasik S, Künzel O, Black A, Conradt C, Kerschbaumer F. Potential economic impact of using a proprietary willow bark extract in outpatient treatment of low back pain: an open non-randomized study. Phytomedicine 2001; 8: 241-251

[40] Chrubasik S, Eisenberg E, Balan E, Weinberger T, Luzzati R, Conradt C. Treatment of low back pain exacerbations with willow bark extract: a randomized double-blind study. Am J Med 2000; 109: 9-14

[41] Manniche C, Asmussen K, Lauritsen B, Vinterberg H, Kreiner S, Jordan A. Low Back Pain Rating scale: validation of a tool for assessment of low back pain. Pain 1994; 57: 317-326

[42] Akao T, Yoshino T, Kobashi K, Hattori M. Evaluation of salicin as an antipyretic prodrug that does not cause gastric injury. Planta Med 2002; 68: 714-718

[43] Meier B, Sticher O, Julkunen-Tiitto R. Pharmaceutical aspects of the use of willows in herbal remedies. Planta Med 1988; 54: 559

[44] Schmid B, Kotter I, Heide L. Pharmacokinetics of salicin after oral administration of a standardised willow bark extract. Eur J Clin Pharmacol 2001; 57: $387-391$

[45] Foetsch G, Pfeifer S. Vergleichende Serumspiegeluntersuchung von Salicylsäure nach oraler Applikation von Salicin bzw. Natriumsalicytalat in Ratten. Pharmazie 1990; 45: 535-536

[46] Higgs GA, Salmon JA, Henderson B, Vane JR. Pharmacokinetics of aspirin and salicylate in relation to inhibition of arachidonate cyclooxygenase and antiinflammatory activity. Proc Natl Acad Sci U S A 1987; 84: 1417-1420

[47] Krivoy N, Pavlotzky E, Chrubasik S, Eisenberg E, Brook G. Effect of salicis cortex extract on human platelet aggregation. Planta Med 2001; 67: 209-212
[48] Shalansky S, Lynd L, Richardson K, Ingaszewski A, Kerr C. Risk of warfarinrelated bleeding events and supratherapeutic international normalized ratios associated with complementary and alternative medicine: a longitudinal analysis. Pharmacotherapy 2007; 27: 1237-1247

[49] Gardner Z, McGuffin M. American Herbal Products Association's botanical safety handbook. Boca Raton: CRC Press; 2013

[50] Jennings A. Link between salicylate and willow bark. Pharm J 2006; 276 : 417

[51] Boullata JI, McDonnell PJ, Oliva CD. Anaphylactic reaction to a dietary supplement containing willow bark. Ann Pharmacother 2003; 37: 832835

[52] Srivali N, Cheungpasitporn W, Chongnarungsin D, Edmonds LC. White willow bark induced acute respiratory distress syndrome. N Am J Med Sci 2013; 5: 330

[53] Baker S, Thomas PS. Herbal medicine precipitating massive haemolysis. Lancet 1987; 1: 1039-1040

[54] Colonna P. Aspirin and glucose-6-phosphate dehydrogenase deficiency. Br Med J (Clin Res Ed) 1981; 283: 1189

[55] Dinakaran D, Bristow E, Armanious H, Garros D, Yap J, Noga M, Sergi C. Co-ingestion of willow bark tea and acetaminophen associated with fatal infantile fulminant liver failure. Pediatr Int 2017; 59: 743-745

[56] German Federal Institute for Risk Assessment (BfR), Unit of Food Toxicology Germany, Matyjaszczyk E, Schumann R. Risk assessment of white willow (Salix alba) in food. EFSA Journal 2018; 16: e16081

[57] Algreen M, Trapp S, Rein A. Phytoscreening and phytoextraction of heavy metals at Danish polluted sites using willow and poplar trees. Environ Sci Pollut Res Int 2014; 21: 8992-9001

[58] Mleczek M, Rissmann I, Rutkowski P, Kaczmarek Z, Golinski P. Accumulation of selected heavy metals by different genotypes of Salix. Environ Exp Bot 2009; 66: 289-296

[59] Van Slycken S, Witters N, Meiresonne L, Meers E, Ruttens A, Van Peteghem P, Weyens N, Tack FM, Vangronsveld J. Field evaluation of willow under short rotation coppice for phytomanagement of metalpolluted agricultural soils. Int J Phytoremediation 2013; 15: 677-689

[60] Gasser U, Klier B, Kuhn A, Steinhoff B. Current findings on the heavy metal content in herbal drugs. Pharmeur Sci Notes 2009; 1: 37-50

[61] European Pharmacopoeia (Ph. Eur.) 9.2. Herbal drugs, general monograph 07/2017: 1433. Available at http://online6.edqm.eu/ep908/. Accessed October 1, 2019 